\title{
RESEARCH
}

Open Access

\section{Distribution of under- 5 deaths in the neonatal, postneonatal, and childhood periods: a multicountry analysis in 64 low- and middle-income countries}

Zhihui Li ${ }^{1,2}$, Omar Karlsson ${ }^{3,4}$, Rockli Kim ${ }^{5,6,7}$ and S. V. Subramanian ${ }^{2,7^{*}}$

\begin{abstract}
Background: As under-5 mortality rates declined all over the world, the relative distribution of under-5 deaths during different periods of life changed. To provide information for policymakers to plan for multi-layer health strategies targeting child health, it is essential to quantify the distribution of under-5 deaths by age groups.

Methods: Using 245 Demographic and Health Surveys from 64 low- and middle-income countries conducted between 1986 and 2018, we compiled a database of 2,437,718 children under-5 years old with 173,493 deaths. We examined the share of deaths that occurred in the neonatal ( $<1$ month), postneonatal (1 month to 1 year old), and childhood ( 1 to 5 years old) periods to the total number of under- 5 deaths at both aggregate- and country-level. We estimated the annual change in share of deaths to track the changes over time. We also assessed the association between share of deaths and Gross Domestic Product (GDP) per capita.

Results: Neonatal deaths accounted for $53.1 \%$ (95\% confidence interval [CI]: $52.7,53.4)$ of the total under-5 deaths. The neonatal share of deaths was lower in low-income countries at $44.0 \%(43.5,44.5)$, and higher in lower-middleincome and upper-middle income countries at $57.2 \%(56.8,57.6)$ and $54.7 \%(53.8,55.5)$ respectively. There was substantial heterogeneity in share of deaths across countries; for example, the share of neonatal to total under-5 deaths ranged from $20.9 \%(14.1,27.6)$ in Eswatini to 82.8\% $(73.0,92.6)$ in Dominican Republic. The shares of deaths in all three periods were significantly associated with GDP per capita, but in different directions - as GDP per capita increased by $10 \%$, the neonatal share of deaths would significantly increase by 0.78 percentage points [PPs] (0.43, 1.13), and the postneonatal and childhood shares of deaths would significantly decrease by 0.29 PPs $(0.04,0.54)$ and 0.49 PPs $(0.24,0.74)$ respectively.
\end{abstract}

Conclusions: Along with the countries' economic development, an increasing proportion of under-5 deaths occurs in the neonatal period, suggesting a need for multi-layer health strategies with potentially heavier investment in newborn health.

Keywords: Low- and middle-income countries, Distribution of under-5 deaths, Heterogeneity across countries

\footnotetext{
* Correspondence: svsubram@hsph.harvard.edu

${ }^{2}$ Department of Social and Behavioral Sciences, Harvard T.H. Chan School of

Public Health, 677 Huntington Avenue, Boston, MA 02115, USA

'Harvard Center for Population and Development Studies, 9 Bow Street, Cambridge, MA 02138, USA

Full list of author information is available at the end of the article
}

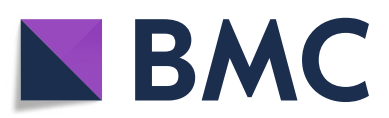

(- The Author(s). 2021 Open Access This article is licensed under a Creative Commons Attribution 4.0 International License, which permits use, sharing, adaptation, distribution and reproduction in any medium or format, as long as you give appropriate credit to the original author(s) and the source, provide a link to the Creative Commons licence, and indicate if changes were made. The images or other third party material in this article are included in the article's Creative Commons licence, unless indicated otherwise in a credit line to the material. If material is not included in the article's Creative Commons licence and your intended use is not permitted by statutory regulation or exceeds the permitted use, you will need to obtain permission directly from the copyright holder. To view a copy of this licence, visit http://creativecommons.org/licenses/by/4.0/ The Creative Commons Public Domain Dedication waiver (http://creativecommons.org/publicdomain/zero/1.0/) applies to the data made available in this article, unless otherwise stated in a credit line to the data. 


\section{Background}

The Millennium Development Goal (MDG) era witnessed an impressive decline in the number of global under- 5 child deaths, which were reduced by $53 \%$ from 12.7 million to 5.9 million deaths between 1990 and 2015 [1]. However, many countries still fell short of the MDG 4 which targeted a two-thirds reduction in under5 mortality during this period [2]. The progress was also uneven across age groups as the reduction in neonatal (in the first month of life) deaths declined slower than deaths of older children [3]. Between 1990 and 2015, neonatal deaths reduced by $39 \%$ from 4.4 million to 2.7 million, compared to a reduction of more than $60 \%$ in postneonatal (between 1 month and 1 year old) and childhood (between 1 and 5 years old) deaths [4, 5].

Under-5 deaths occurring at different ages have different causes that, correspondingly, require different interventions [6-8]. Several multicountry studies have disaggregated deaths of children under- 5 years old by age group, examining the mortality rates in neonatal, postneonatal, and childhood periods, separately [9-12]. The importance of disaggregating deaths by age group was also reflected in the Sustainable Development Goals (SDGs) where reducing neonatal mortality (SDG 3.2.2) to 12 deaths per 1000 livebirths, was explicitly listed as one of the goals, separately from reducing under-5 mortality (SDG 3.2.1) to 25 deaths per 1000 livebirths [13].

However, existing studies and major health agendas have almost exclusively focused on the mortality rate indicators [9-12]. Mortality rate, although important in presenting the absolute likelihood of dying at each age, does not provide a clear insight into how the burden of under-5 deaths is distributed by age, and how that distribution changes over time. Exceptions are UNICEF reports that found that under-5 deaths were increasingly concentrated in the neonatal period [14-16]. Yet, these reports were limited to regional-level analyses, which are insufficient to reflect important heterogeneity across countries.

For governments to establish multi-layered health strategies with proper sets of interventions to reduce under-5 deaths, it is essential to examine which age groups have the highest burden of deaths, how the relative burden has changed over time, and how it varies by level of national income. This paper seeks to estimate the distribution of the burden of deaths using the "share" indicators; specifically, we will estimate the share of under-5 deaths occurring in the neonatal, postneonatal, and childhood periods. To our knowledge, the "share" indicator was first used in the field of health two decades ago, but has been applied only in a couple of studies which identified the burden of deaths attributable to non-communicable diseases, compared to communicable diseases, among various population groups [17-19].
Globally, the share of deaths from non-communicable diseases has been rising, particularly in rich countries, with a corresponding shift in intervention emphasis. Similarly, the increased concentration of under -5 deaths in the neonatal period might also call for increased attention to mitigate the causes of neonatal deaths. While the importance of this shift in emphasis is not disputed, an understanding of the variation in the share of under5 deaths occurring at different ages between countries and over time needs to be established first, in order to tailor policy response and resources appropriately, since neonatal, postneonatal, and childhood deaths may have somewhat different underlying causes.

In this study, besides estimating the share of under-5 deaths occurring in the neonatal, postneonatal, and childhood periods respectively, we analyze how the shares of under-5 deaths in the respective ages varied according to the level of economic development, and how it has shifted over time. The current paper provides by far the most comprehensive picture of the levels and trends in the distribution of under- 5 deaths.

\section{Methods}

\section{Data sources}

This study used data from the nationally representative Demographic and Health Survey (DHS) conducted between 1986 and 2018 in 64 low- and middle-income countries (Additional file 1: Table 1). The DHS has been widely adopted as a reliable data source for measuring mortality among children under -5 years old across developing countries [20-22]. The DHS uses extensive interviewer training, standardized measurement tools and techniques, an identical core questionnaire, and instrument pretesting to ensure standardization and comparability across diverse sites and time [20, 23]. The DHS adopts a multistage stratified sampling design, with the first stage generally involving choosing geographicallydefined units such as villages or neighborhoods, and the second stage involving selecting the specific households or persons to be interviewed [23, 24]. Details on survey sampling, data collection, and data processing can be found in the countries' final reports, available from the Measure DHS website [23].

The GDP per capita used in the analysis was corrected for purchasing power parity and was in constant 2011 US $\$$ and were obtained from the World Bank $[25,26]$. For each country, we adopted the GDP per capita of their survey year. We identified whether the country was a low-income country (LIC), a lower-middle-income country (LMIC), or a upper-middle income country (UMIC) in the survey year according to the World Bank classification [27].

This project used publicly-accessible secondary data obtained from the DHS website (https://dhsprogram. 
Table 1 Share of neonatal, postneonatal, and childhood to total under-5 deaths at aggregate-level, latest survey rounds

\begin{tabular}{llll}
\hline & Neonatal & Postneonatal & Childhood \\
\hline $\begin{array}{llll}\text { All available countries } \\
\text { By income class }\end{array}$ & $53.1(52.7,53.4)$ & $28.4(28.1,28.8)$ & $18.5(18.2,18.9)$ \\
$\quad$ & & $32.8(32.3,33.3)$ & $23.2(22.7,23.7)$ \\
Low-income countries & $44.0(43.5,44.5)$ & $26.1(25.7,26.5)$ & $16.7(16.3,17.1)$ \\
Lower-middle-income countries & $57.2(56.8,57.6)$ & $33.0(32.2,33.9)$ & $12.3(11.6,13.0)$ \\
Upper-middle-income countries & $54.7(53.8,55.5)$ & & \\
\hline
\end{tabular}

conm/data/available-datasets.cfm). The DHS data are not collected specifically for this study and no one on the study team has access to identifiers linked to the data. These activities do not meet the regulatory definition of human subjects research. As such, IRB review is not required. The Harvard Longwood Campus IRB allows researchers to self-determine when their research does not meet the requirements for IRB oversight via the online IRB Decision Tool.

\section{Study population and sample size}

This study restricted the analysis to children born alive within 5 years before the interview. We excluded all surveys with 0 recorded deaths in any period of life (i.e. Armenia 2010, Armenia 2015, Colombia 1986, Moldova 2005, and Vietnam 2002). We also excluded countries with the latest surveys conducted before 2000 to ensure the information were up to date. In total, we included 245 DHS surveys for 64 countries between 1986 and 2018. Our analysis involved a total of $2,437,718$ children under- 5 years old. We identified a total of 173,493 deaths, with 73,459 of them occurring in the neonatal period, 58,219 occurring in the postneonatal period, and 41,815 occurring in the childhood period.

\section{Measures}

Estimating the share of deaths in each age group allowed us to investigate the distribution of under-5 deaths across ages. In this study, we involved three indicators to measure share of deaths in each period, including share of neonatal to total under-5 deaths (or "neonatal share of deaths"), share of postneonatal to total under- 5 deaths (or "postneonatal share of deaths"), and share of childhood to total under-5 deaths (or "childhood share of deaths"), defined as the percentage of under-5 deaths occurring in the neonatal, postneonatal, or childhood period for a certain cohort.

\section{Statistical analysis}

We examined the share of deaths at both aggregate- and country-levels. For analysis at country-level, we examined the latest shares of deaths in 64 countries using the most recent DHS data since 2000. The mean of the latest years was 2013. The median was 2014, with interquartile ranges between 2012 and 2016. We used "stset" command in Stata version 14.2 to trace the number of deaths during the neonatal, postneonatal, and childhood periods for a synthetic cohort based on a reference period of 5 years preceding the survey. We applied DHS sampling weights in the analysis. Following previous practice, we used the bootstrap method by drawing 1000 samples to produce the standard errors and $95 \%$ confidence intervals (CIs) for the point estimates [28, 29].

We also tracked the changes in share of deaths over time for each country with available data in multiple survey years. Among the 64 countries involved in the study, we identified 50 countries with multiple surveys conducted between 1986 and 2018. The mean of the gaps between the latest and the earliest surveys was 20 years. The median was 21 years and an interquartile range of 16 and 26 years. We generated annual change in neonatal, postneonatal, and childhood share of deaths, as well as the $95 \%$ CIs using the lincom post-estimation commands in Stata.

For analyses at aggregate-level, we pooled the observations from the latest surveys for the 64 countries. We followed previous practice [30] and reweighted the observations in each survey in proportion to the country's population size at the time of survey. The population size was obtained from the World Bank data [31]. The rest of the procedure to generate the point estimates and 95\% CIs of the share of deaths was the same as at country-level.

\section{Results}

\section{Aggregate-level share of deaths}

Using pooled data from 64 countries, we show the share of deaths in each period in Table 1. We found that among all under- 5 deaths, $53.1 \%$ (95\% CI: $52.7,53.4)$ occurred in the neonatal period, $28.4 \%$ (95\% CI: 28.1, 28.8) were in the postneonatal period, and $18.5 \%$ (95\% CI: $18.2,18.9)$ were in the childhood period. Countries with higher income appeared to have significantly larger neonatal share of deaths - in LICs, $44.0 \%$ (95\% CI: 43.5 , 44.5) of the under-5 deaths happened in the neonatal period, compared to $57.2 \%$ (95\% CI: $56.8,57.6$ ) in LMICs and $54.7 \%(95 \%$ CI: $53.8,55.5)$ in UMICs. On the other hand, childhood share of deaths decreased in countries with higher income level - in LICs, 23.2\% (95\% CI: 22.7, 23.7) of the under-5 deaths occurred in the childhood 
Table 2 Share of neonatal, postneonatal, and childhood to total under-5 deaths, and their ranks among 64 countries, latest survey rounds

\begin{tabular}{|c|c|c|c|c|c|c|c|c|}
\hline \multirow[t]{2}{*}{ Country } & \multirow[t]{2}{*}{ Year } & \multirow[t]{2}{*}{ Income } & \multicolumn{2}{|c|}{$\begin{array}{l}\text { Neonatal to total under- } 5 \\
\text { deaths }\end{array}$} & \multicolumn{2}{|c|}{$\begin{array}{l}\text { Postneonatal to total under- } 5 \\
\text { deaths }\end{array}$} & \multicolumn{2}{|c|}{$\begin{array}{l}\text { Childhood to total under-5 } \\
\text { deaths }\end{array}$} \\
\hline & & & Share (\%) & Rank & Share (\%) & Rank & Share (\%) & Rank \\
\hline Dominican Republic & 2013 & UM & $82.8(73.0,92.6)$ & 1 & $5.2(-0.6,10.9)$ & 64 & $12.1(3.6,20.5)$ & 41 \\
\hline Kyrgyzstan & 2012 & $L$ & $77.6(65.7,89.4)$ & 2 & $14.3(4.4,24.2)$ & 63 & $8.2(0.4,15.9)$ & 57 \\
\hline Morocco & 2003 & LM & $72.4(63.6,81.3)$ & 3 & $21.4(13.3,29.6)$ & 60 & $6.1(1.4,10.9)$ & 63 \\
\hline Honduras & 2011 & LM & $69.9(61.0,78.8)$ & 4 & $19.4(11.7,27.1)$ & 61 & $10.7(4.7,16.7)$ & 47 \\
\hline Turkey & 2008 & UM & $68.0(49.3,86.7)$ & 5 & $16.0(1.3,30.7)$ & 62 & $16.0(1.3,30.7)$ & 38 \\
\hline Bangladesh & 2014 & LM & $67.5(60.1,75.0)$ & 6 & $23.4(16.7,30.1)$ & 55 & $9.1(4.5,13.6)$ & 53 \\
\hline India & 2015 & LM & $66.4(65.1,67.7)$ & 7 & $23.3(22.1,24.4)$ & 56 & $10.3(9.5,11.1)$ & 50 \\
\hline Azerbaijan & 2006 & LM & $65.5(53.2,77.9)$ & 8 & $25.9(14.5,37.2)$ & 50 & $8.6(1.3,15.9)$ & 55 \\
\hline Armenia & 2005 & LM & $65.5(47.9,83.1)$ & 9 & $27.6(11.0,44.1)$ & 45 & $6.9(-2.5,16.3)$ & 60 \\
\hline Jordan & 2017 & UM & $64.2(54.5,73.9)$ & 10 & $29.5(20.3,38.7)$ & 38 & $6.3(1.4,11.2)$ & 62 \\
\hline Cambodia & 2014 & $L$ & $64.0(55.2,72.9)$ & 11 & $25.4(17.4,33.5)$ & 52 & $10.5(4.9,16.2)$ & 49 \\
\hline Pakistan & 2017 & LM & $63.7(59.1,68.3)$ & 12 & $28.0(23.7,32.3)$ & 43 & $8.3(5.7,11.0)$ & 56 \\
\hline Senegal & 2017 & $\mathrm{~L}$ & $62.9(56.3,69.6)$ & 13 & $25.9(19.8,31.9)$ & 51 & $11.2(6.9,15.6)$ & 46 \\
\hline Ghana & 2014 & LM & $61.9(52.6,71.2)$ & 14 & $21.9(14.0,29.9)$ & 58 & $16.2(9.1,23.3)$ & 37 \\
\hline Guyana & 2009 & LM & $61.1(45.0,77.3)$ & 15 & $36.1(20.2,52.0)$ & 15 & $2.8(-2.7,8.2)$ & 64 \\
\hline Philippines & 2017 & LM & $61.0(52.2,69.9)$ & 16 & $27.1(19.1,35.2)$ & 47 & $11.9(6.0,17.7)$ & 42 \\
\hline Peru & 2012 & UM & $59.4(47.7,71.1)$ & 17 & $30.4(19.5,41.4)$ & 32 & $10.1(3.0,17.3)$ & 51 \\
\hline Yemen & 2013 & LM & $59.3(54.2,64.3)$ & 18 & $29.2(24.6,33.9)$ & 39 & $11.5(8.2,14.7)$ & 44 \\
\hline Colombia & 2015 & UM & $59.0(48.0,70.0)$ & 19 & $32.1(21.6,42.5)$ & 27 & $9.0(2.6,15.4)$ & 54 \\
\hline Nepal & 2016 & $\mathrm{~L}$ & $56.5(46.3,66.7)$ & 20 & $37.0(27.0,46.9)$ & 9 & $6.5(1.4,11.6)$ & 61 \\
\hline Guatemala & 2014 & LM & $56.2(49.2,63.3)$ & 21 & $32.3(25.7,38.9)$ & 26 & $11.5(6.9,16.0)$ & 45 \\
\hline Indonesia & 2017 & LM & $56.2(49.8,62.6)$ & 22 & $27.5(21.7,33.2)$ & 46 & $16.3(11.6,21.1)$ & 36 \\
\hline Bolivia & 2008 & LM & $55.4(49.2,61.5)$ & 23 & $36.7(30.7,42.6)$ & 11 & $8.0(4.6,11.3)$ & 58 \\
\hline Egypt & 2014 & LM & $55.2(48.6,61.7)$ & 24 & $35.0(28.7,41.3)$ & 17 & $9.9(5.9,13.8)$ & 52 \\
\hline Malawi & 2015 & $L$ & $54.6(50.0,59.2)$ & 25 & $26.5(22.4,30.6)$ & 49 & $18.9(15.2,22.5)$ & 30 \\
\hline Comoros & 2012 & $\mathrm{~L}$ & $54.5(43.4,65.7)$ & 26 & $28.6(18.4,38.7)$ & 41 & $16.9(8.5,25.3)$ & 35 \\
\hline Myanmar & 2015 & LM & $53.2(43.1,63.3)$ & 27 & $36.2(26.4,45.9)$ & 13 & $10.6(4.4,16.9)$ & 48 \\
\hline Uganda & 2016 & $L$ & $52.7(47.3,58.2)$ & 28 & $28.7(23.8,33.6)$ & 40 & $18.6(14.4,22.8)$ & 31 \\
\hline Timor-Leste & 2016 & LM & $52.7(44.1,61.4)$ & 29 & $23.3(15.9,30.6)$ & 57 & $24.0(16.6,31.4)$ & 15 \\
\hline Gambia & 2013 & $L$ & $51.6(44.4,58.9)$ & 30 & $33.0(26.1,39.8)$ & 23 & $15.4(10.1,20.6)$ & 40 \\
\hline Gabon & 2012 & UM & $51.3(43.3,59.3)$ & 31 & $21.7(15.1,28.3)$ & 59 & $27.0(19.9,34.1)$ & 10 \\
\hline Ethiopia & 2016 & $L$ & $51.1(46.3,55.8)$ & 32 & $30.4(26.0,34.8)$ & 33 & $18.5(14.8,22.2)$ & 32 \\
\hline Angola & 2015 & UM & $50.6(45.3,55.9)$ & 33 & $29.7(24.8,34.6)$ & 37 & $19.7(15.5,23.9)$ & 27 \\
\hline Zimbabwe & 2015 & $L$ & $50.5(43.8,57.1)$ & 34 & $30.1(24.0,36.2)$ & 35 & $19.4(14.2,24.7)$ & 28 \\
\hline Papua New Guinea & 2017 & LM & $49.1(42.5,55.7)$ & 35 & $32.9(26.7,39.1)$ & 24 & $18.0(13.0,23.1)$ & 34 \\
\hline Lesotho & 2014 & LM & $49.0(39.4,58.7)$ & 36 & $31.7(22.7,40.7)$ & 28 & $19.2(11.6,26.8)$ & 29 \\
\hline Kenya & 2014 & LM & $48.7(44.2,53.2)$ & 37 & $35.5(31.2,39.9)$ & 16 & $15.7(12.4,19.0)$ & 39 \\
\hline Togo & 2013 & $\mathrm{~L}$ & $47.7(40.3,55.1)$ & 38 & $27.6(20.9,34.2)$ & 44 & $24.7(18.3,31.1)$ & 14 \\
\hline Rwanda & 2014 & $\mathrm{~L}$ & $47.5(40.1,54.8)$ & 39 & $31.3(24.5,38.1)$ & 29 & $21.2(15.2,27.2)$ & 24 \\
\hline Haiti & 2016 & $L$ & $47.1(40.5,53.7)$ & 40 & $34.5(28.3,40.8)$ & 18 & $18.4(13.3,23.5)$ & 33 \\
\hline Afghanistan & 2015 & $L$ & $46.9(43.5,50.2)$ & 41 & $45.4(42.1,48.8)$ & 2 & $7.7(5.9,9.5)$ & 59 \\
\hline Tanzania & 2015 & $L$ & $46.6(40.6,52.6)$ & 42 & $31.2(25.6,36.8)$ & 30 & $22.2(17.2,27.2)$ & 20 \\
\hline
\end{tabular}


Table 2 Share of neonatal, postneonatal, and childhood to total under-5 deaths, and their ranks among 64 countries, latest survey rounds (Continued)

\begin{tabular}{|c|c|c|c|c|c|c|c|c|}
\hline \multirow[t]{2}{*}{ Country } & \multirow[t]{2}{*}{ Year } & \multirow[t]{2}{*}{ Income } & \multicolumn{2}{|c|}{$\begin{array}{l}\text { Neonatal to total under-5 } \\
\text { deaths }\end{array}$} & \multicolumn{2}{|c|}{$\begin{array}{l}\text { Postneonatal to total under-5 } \\
\text { deaths }\end{array}$} & \multicolumn{2}{|c|}{$\begin{array}{l}\text { Childhood to total under-5 } \\
\text { deaths }\end{array}$} \\
\hline & & & Share (\%) & Rank & Share (\%) & Rank & Share (\%) & Rank \\
\hline Sao Tome and Principe & 2008 & LM & $46.5(31.4,61.6)$ & 43 & $30.2(16.3,44.1)$ & 34 & $23.3(10.5,36.0)$ & 18 \\
\hline Mali & 2018 & L & $44.8(40.1,49.6)$ & 44 & $24.4(20.3,28.5)$ & 53 & $30.8(26.4,35.1)$ & 5 \\
\hline Nicaragua & 2001 & L & $44.8(35.2,54.3)$ & 45 & $33.3(24.3,42.4)$ & 20 & $21.9(14.0,29.9)$ & 21 \\
\hline Côte d'Ivoire & 2011 & LM & $44.5(38.8,50.2)$ & 46 & $33.2(27.8,38.6)$ & 21 & $22.3(17.5,27.0)$ & 19 \\
\hline Tajikistan & 2017 & L & $44.1(34.9,53.4)$ & 47 & $44.1(34.9,53.4)$ & 3 & $11.7(5.7,17.7)$ & 43 \\
\hline Congo & 2011 & LM & $44.1(37.5,50.7)$ & 48 & $26.8(21.0,32.7)$ & 48 & $29.1(23.1,35.1)$ & 8 \\
\hline Zambia & 2013 & LM & $43.4(38.5,48.2)$ & 49 & $33.1(28.5,37.7)$ & 22 & $23.6(19.4,27.7)$ & 16 \\
\hline Benin & 2017 & L & $43.0(38.5,47.5)$ & 50 & $29.9(25.7,34.0)$ & 36 & $27.1(23.1,31.1)$ & 9 \\
\hline Madagascar & 2008 & L & $42.6(37.4,47.8)$ & 51 & $36.9(31.9,42.0)$ & 10 & $20.5(16.2,24.7)$ & 25 \\
\hline Nigeria & 2018 & LM & $42.0(39.6,44.4)$ & 52 & $24.0(21.9,26.1)$ & 54 & $34.0(31.7,36.4)$ & 2 \\
\hline Liberia & 2013 & L & $38.3(31.7,44.9)$ & 53 & $32.5(26.2,38.9)$ & 25 & $29.2(23.0,35.4)$ & 7 \\
\hline Burundi & 2016 & L & $38.1(33.7,42.6)$ & 54 & $37.0(32.6,41.5)$ & 8 & $24.8(20.9,28.8)$ & 13 \\
\hline Mozambique & 2011 & $L$ & $37.6(33.0,42.3)$ & 55 & $41.0(36.3,45.7)$ & 6 & $21.3(17.4,25.3)$ & 23 \\
\hline Democratic Republic of the Congo & 2013 & L & $37.6(34.0,41.2)$ & 56 & $36.3(32.7,39.9)$ & 12 & $26.1(22.8,29.4)$ & 11 \\
\hline Namibia & 2013 & UM & $35.9(26.6,45.2)$ & 57 & $42.7(33.1,52.3)$ & 4 & $21.4(13.4,29.3)$ & 22 \\
\hline Cameroon & 2011 & LM & $35.8(31.6,40.0)$ & 58 & $31.0(27.0,35.1)$ & 31 & $33.2(29.1,37.3)$ & 3 \\
\hline Chad & 2014 & $L$ & $35.6(32.6,38.6)$ & 59 & $33.7(30.7,36.7)$ & 19 & $30.7(27.8,33.6)$ & 6 \\
\hline Guinea & 2018 & L & $35.3(29.8,40.8)$ & 60 & $38.8(33.1,44.4)$ & 7 & $26.0(20.9,31.0)$ & 12 \\
\hline Sierra Leone & 2013 & L & $35.2(31.8,38.5)$ & 61 & $41.5(38.0,45.0)$ & 5 & $23.3(20.3,26.3)$ & 17 \\
\hline Burkina Faso & 2010 & L & $31.0(27.5,34.4)$ & 62 & $36.2(32.6,39.7)$ & 14 & $32.9(29.4,36.3)$ & 4 \\
\hline Niger & 2012 & $L$ & $28.6(24.9,32.2)$ & 63 & $28.1(24.4,31.7)$ & 42 & $43.4(39.3,47.4)$ & 1 \\
\hline Eswatini & 2006 & LM & $20.9(14.1,27.6)$ & 64 & $59.0(50.8,67.2)$ & 1 & $20.1(13.5,26.8)$ & 26 \\
\hline
\end{tabular}

1. Income classification: "L" represents "low-income country"; "LM" represents "lower-middle-income country"; "UM" represents "upper-middle-income country"

period, which reduced to $16.7 \%$ (95\% CI: $16.3,17.1)$ in LMICs, and further reduced to $12.3 \%$ (95\% CI: 11.6, 13.0) in UMICs (Table 1). When we narrowed down the countries with the latest surveys conducted between 2008 and 2018 (Additional file 1: Table 2) or included the countries with 0 recorded deaths in any period of life (Additional file 1: Table 3), the results remained similar.

\section{Country-level share of deaths, latest years}

We presented the latest share of deaths in each country in Table 2. The neonatal share of deaths ranged widely from as low as 20.9\% (95\% CI: 14.1, 27.6) in Eswatini to as high as $82.8 \%$ (95\% CI: 73.0, 92.6) in Dominican Republic; similarly, the postneonatal share of deaths ranged from 5.2\% (95\% CI: $-0.6,10.9)$ in Dominican Republic to $59.0 \%$ (95\% CI: 50.8, 67.2) in Eswatini; and the childhood share of deaths ranged from $2.8 \%$ (95\% CI: -2.7 , $8.2)$ in Guyana to $43.4 \%(39.3,47.4)$ in Niger.

Among the top 10 countries with the highest neonatal share of deaths, only one country was LIC, which was Kyrgyzstan; however, seven of the bottom 10 countries with the lowest neonatal share of deaths were LICs, suggesting LICs were more likely to have a smaller share of neonatal deaths. On the contrary, eight of the top 10 countries with the highest postneonatal share of deaths and six of the top 10 countries with the highest childhood share of deaths were LICs, while few countries with the lowest postneonatal or childhood share of deaths were LICs, indicating LICs were more likely to have a larger proportion of child deaths concentrated in the postneonatal and childhood periods (Table 2).

In Fig. 1, we further examined the association between countries' GDP per capita and share of deaths. We found neonatal share of deaths to be significantly and positively associated with GDP per capita - a 10\% greater GDP per capita was associated with a 0.78 percentage points [PPs] $(95 \% \mathrm{CI}: 0.43,1.13)$ increase in neonatal share of deaths $(P<0.001)$. On the other hand, GDP per capita was negatively associated with postneonatal and childhood shares of deaths: a 10\% greater GDP per capita was associated with a 0.29 PPs (95\% CI: 0.04, $0.54)$ lower postneonatal share of deaths $(P<0.001)$ and 


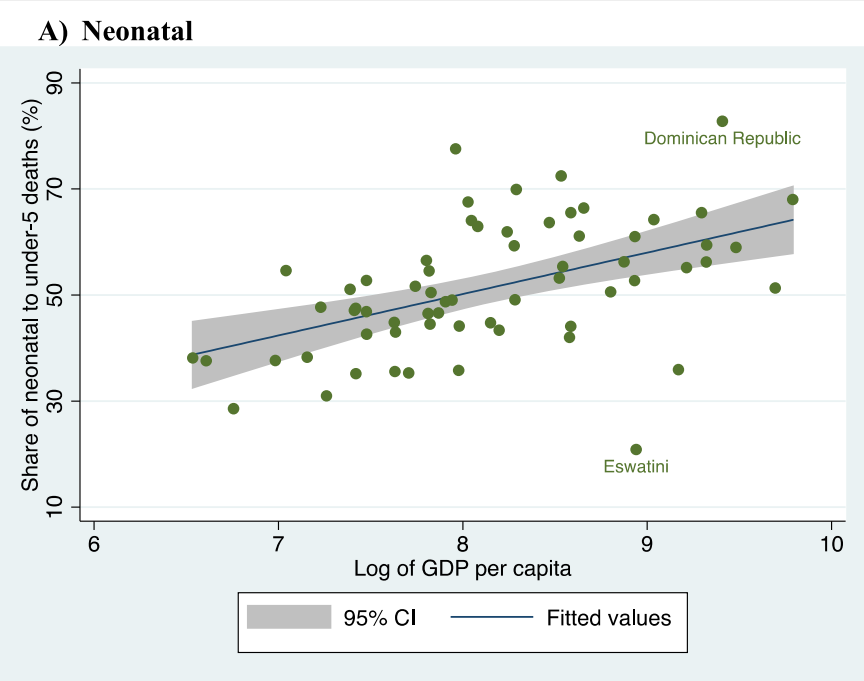

\section{B) Postneonatal}

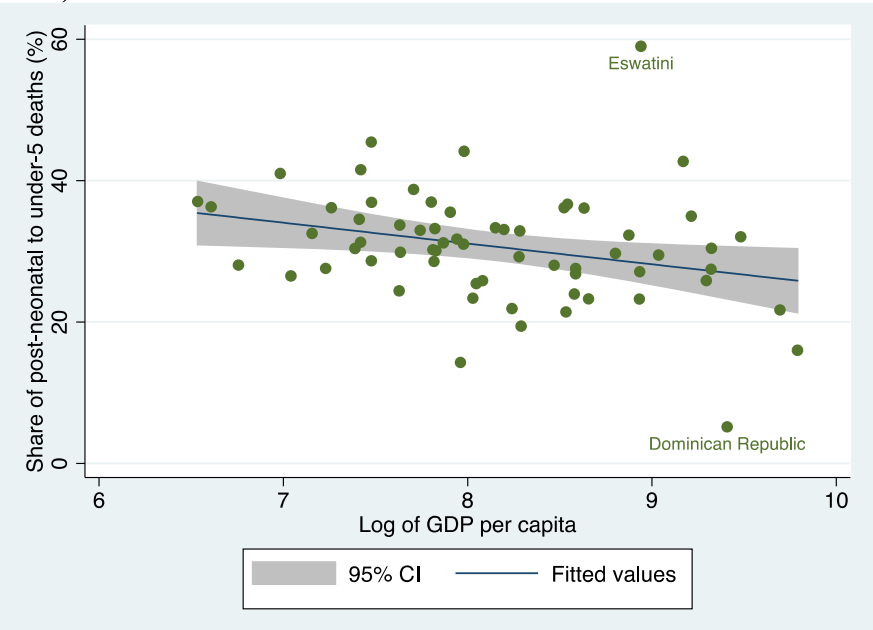

C) Childhood

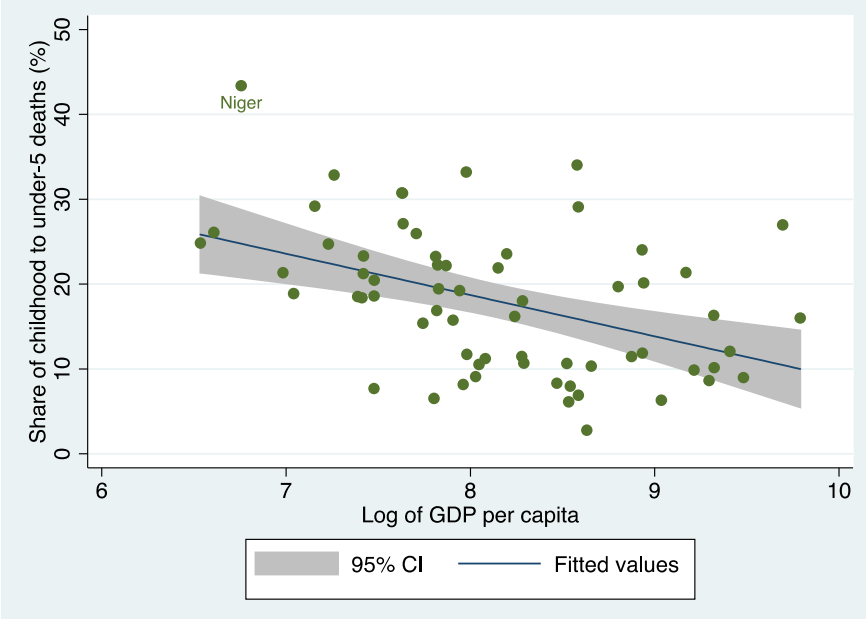

Fig. 1 Correlation between GDP per capita (PPP, constant 2011 international \$) and share of neonatal, postneonatal, childhood to total under-5 deaths (\%), latest survey rounds. a Neonatal. b Postneonatal. c Childhood 
0.49 PPs (95\% CI: 0.24, 0.74) lower childhood share of deaths $(P<0.001)$.

\section{Country-level share of deaths over time}

For the 50 countries with multiple survey rounds, we examined the change in share of deaths over time in Additional file 1: Tables 4 to 6 and showed the annualized change in Figs. 2, 3 and 4. Among the 50 countries, neonatal share of deaths significantly increased in 28 countries which belonged to various income groups (low-, lower-middle-, or upper-middle- income groups). The annual change increased fastest in Cambodia (2.0 PPs [95\% CI: 1.3, 2.7]), followed by Timor-Leste (1.7 [95\% CI: 0.1, 3.2]) and Congo (1.6 [95\% CI: 0.1, 3.1]. Meanwhile, the neonatal share of deaths only significantly decreased in two countries, which were Namibia, and Nepal at an annual rate of -0.8 PPs (95\% CI: - 1.4, 0.2 ) and -0.8 PPs (95\% CI: $-1.4,-0.1)$ respectively.
Moreover, we found postneonatal share of deaths significantly increased in only one country (Nepal), but significantly decreased in 17 countries; similarly, childhood share of deaths significantly increased in merely four countries (Congo, Lesotho, Liberia, and Mozambique), but decreased in 19 countries of different income groups.

\section{Discussion}

To our knowledge, this study is the first to systematically examine the distribution of under- 5 deaths in different periods of life. There were three salient findings of this study: First, at the aggregate-level, more than half of the under-5 deaths occurred in the neonatal period; the neonatal share of deaths was considerably lower in LICs than in LMICs and UMICs, meanwhile, the childhood share of deaths was higher in LICs than the better-off countries. Second, at the country-level, we found

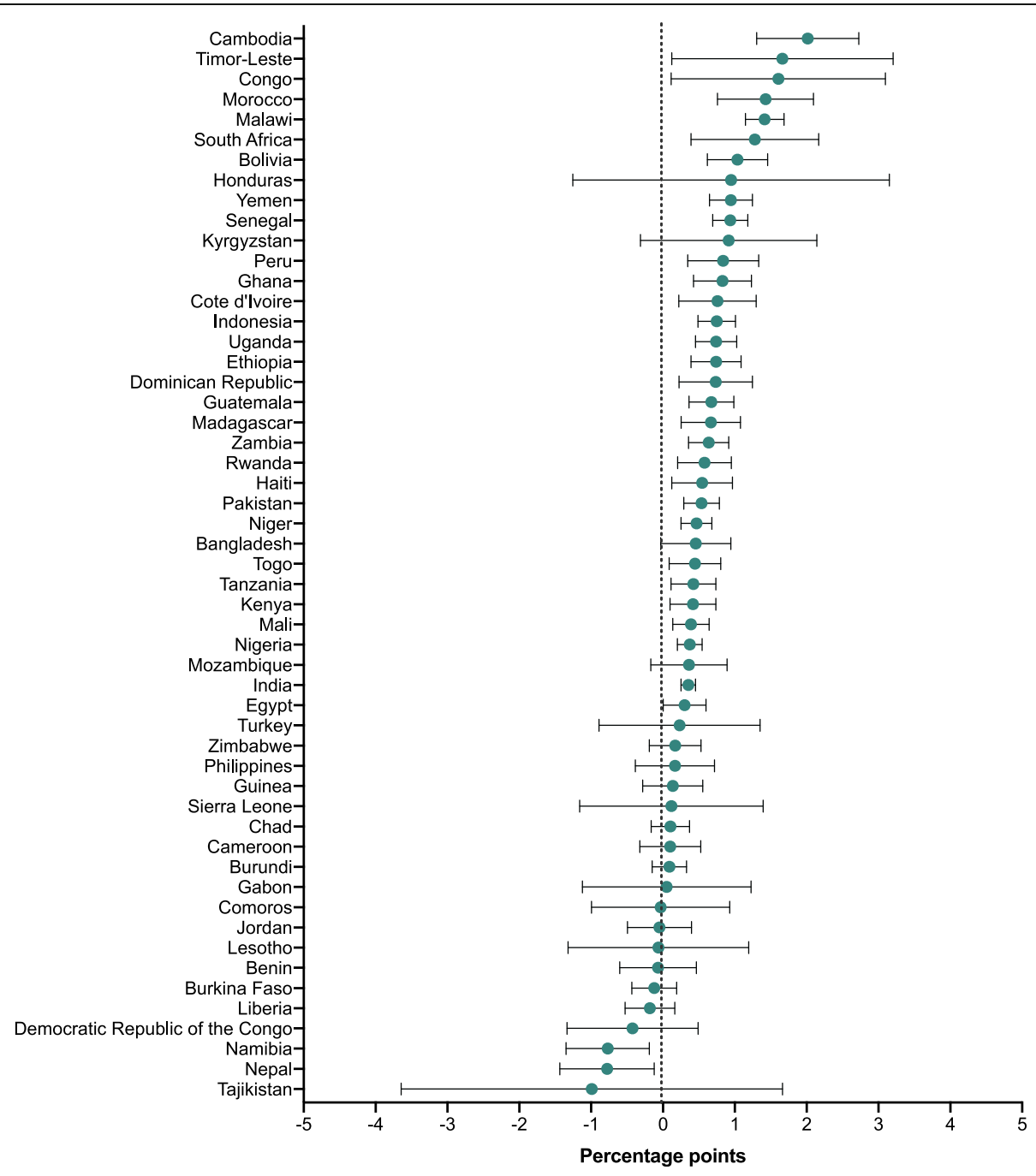

Fig. 2 Annual change in share of neonatal to total under-5 deaths (percentage points) 


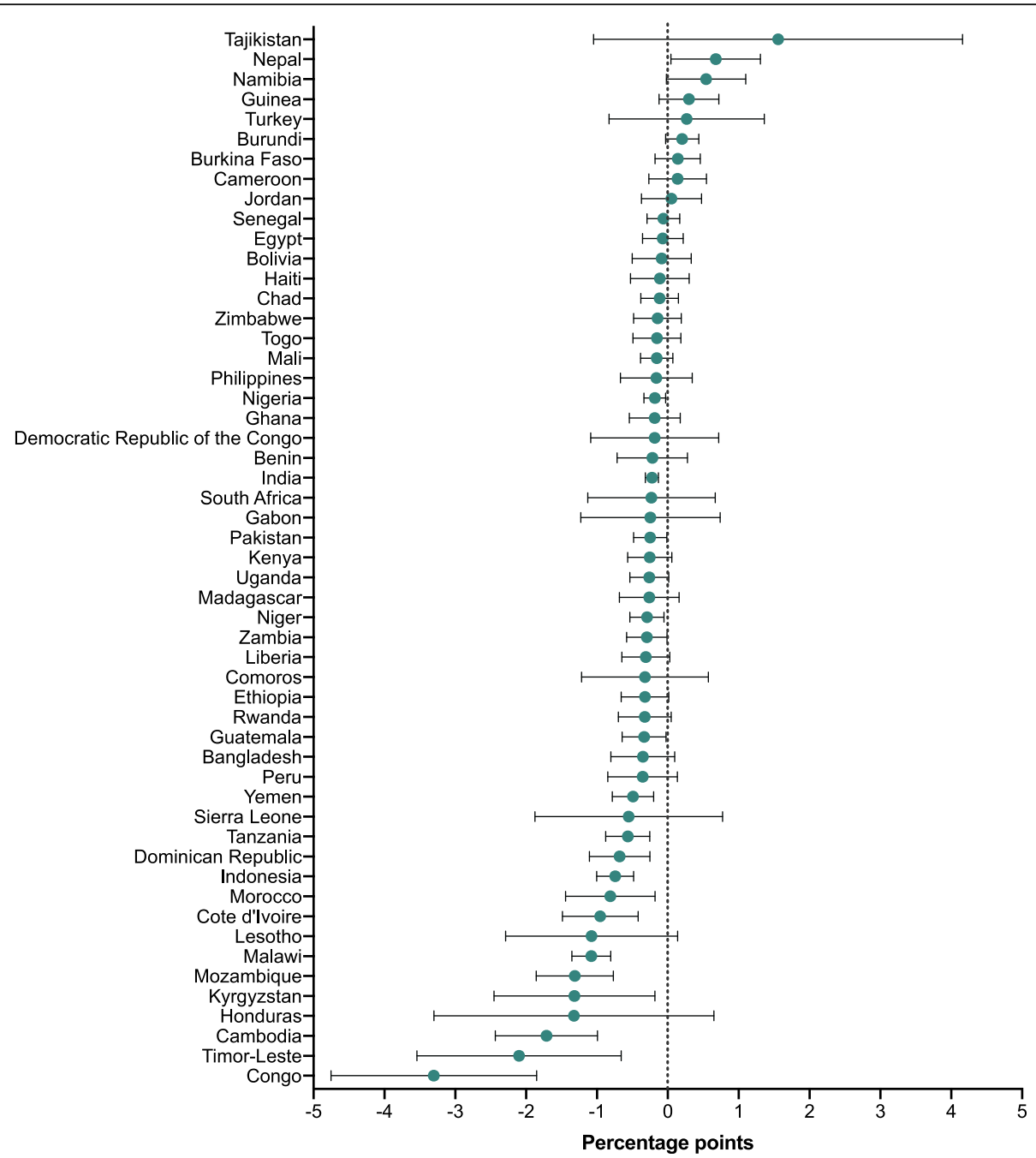

Fig. 3 Annual change in share of postneonatal to total under-5 deaths (percentage points)

substantial heterogeneity across countries with consistent findings as in the aggregate results. Third, under-5 deaths became increasingly concentrated in the neonatal period over time in around half of the studied countries, which was not limited to countries of any certain economic status.

Although there has been increasing interest in examining children's survival disparately by age group [9-12], our study was the first to provide an intuitive picture of how under- 5 deaths are distributed across various age groups, both at aggregate- and country-levels, and how this distribution varies by level of GDP and over time. Such information is a critical addition to the traditional evidence on mortality rates; for instance, although the evidence on mortality rate showed that Ethiopia reached the MDG 4 target to reduce under- 5 mortality rate by two thirds 3 years before the 2015 deadline [12], it overlooked the fact that the share of neonatal to total under- 5 deaths increased from 39\% in 2000 to 51\% in 2016. The increased proportion was not a bad signal for the country, in fact, it was likely to be a result of the country's remarkable progress in reducing child deaths in the postneonatal and childhood periods. Yet with the increasing share of neonatal deaths, in order to achieve the SDG 3.2.2 of reducing neonatal mortality to 12 deaths per 1000 live births or less by 2030 , we call for more attention to address newborn health in the future development of Ethiopia's healthcare system. Nepal has performed outstandingly in the MDG era by achieving the MDG 4 in 2010 and was among the only two countries with a decreasing neonatal share of deaths [32]. The accomplishment can be largely attributed to Nepal's multi-layered health strategies, which started from promoting reproductive, maternal and child services in 1980s, and gradually extended its focus to neonatal health in 2000s. Nepal's health care system heavily relied on the community-based health network composed of 


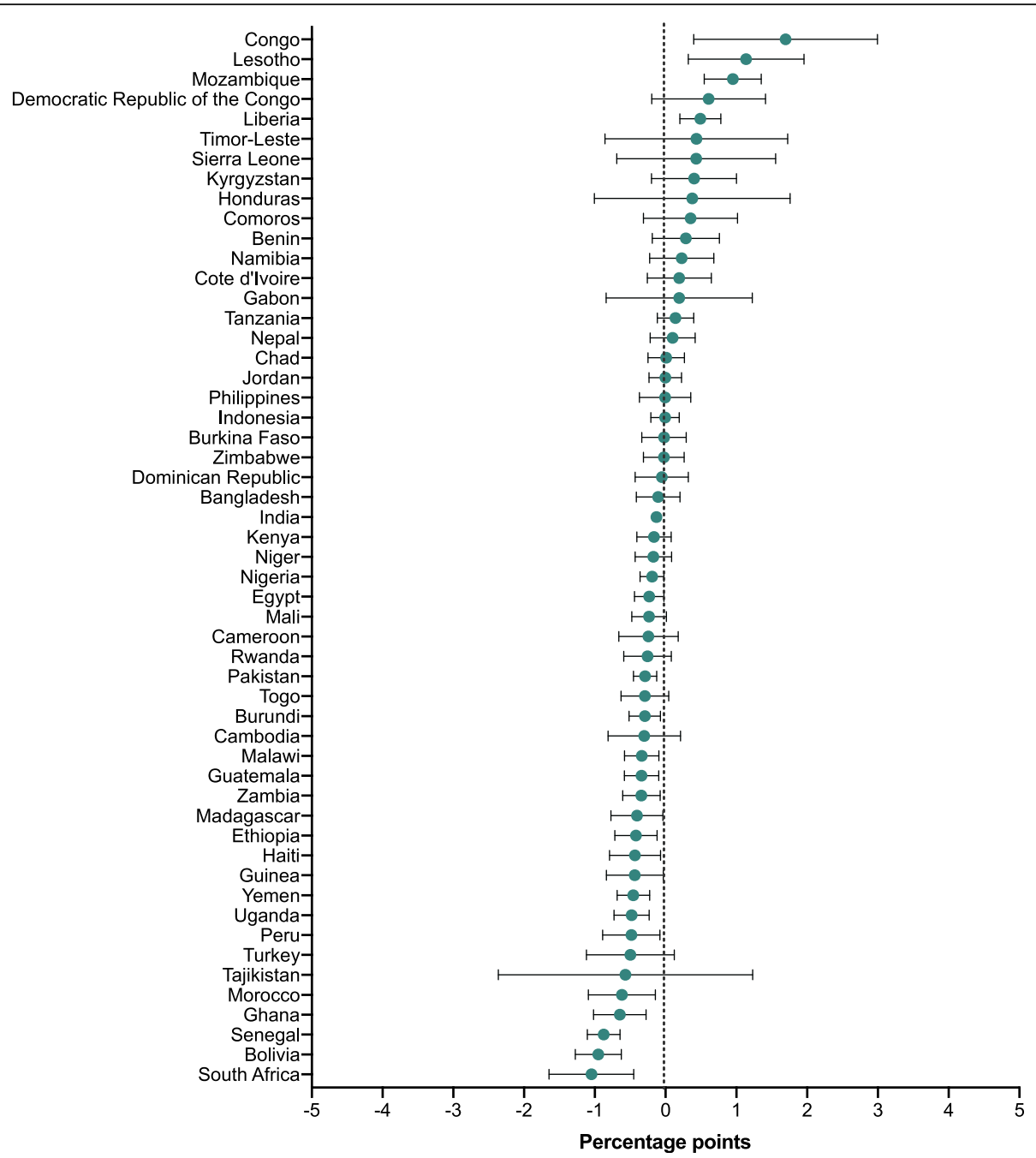

Fig. 4 Annual change in share of childhood to total under-5 deaths (percentage points)

community-based health workers (CHWs), female community health volunteers, traditional birth attendants, and the civil society to reach the most disadvantaged population [33, 34]. Based on this well-functioning communitybased health system, in 2004, Nepal adopted its National Neonatal Health Strategy, and later in 2007, further adopted the Community-Based Newborn Care Program, which delivered essential perinatal and newborn care through the community health network [34, 35]. Various other interventions to reduce neonatal deaths have also been addressed in previous literatures [32,36], such as sufficient antenatal care, institutional delivery, delivery with skilled birth attendants, and timely postnatal check for newborns. Recent evidence from low- and middleincome countries in Africa, Asia and Latin America also pointed to the importance of quality of care, adherence to health guidelines, access to adequate inter-facility transport for emergency obstetric care, and availability of neonatal intensive care [32, 37, 38].
Our work by no means discourage investment in postneonatal and childhood health. Actually, we believe that neonatal, postneonatal and childhood health could be promoted in an integral way, despite the recognized differences in various child development periods. For countries with higher burden of deaths concentrated among older children (e.g. Niger and Nigeria), interventions such as prevention and treatment of pneumonia and diarrhea, complementary feeding, immunizations, nutritional supplementation, improvement in hygiene, and case management of HIV and malaria showed salient effects on children's survival [6-8]. Many of these interventions could be carried out by the community health network or via community-based activities [39, 40]. For example, CHWs were found to be effective in different types of prevention interventions, such as malaria prevention, health education, breastfeeding promotion, essential newborn care and psychosocial support, which are cited as some of the most cost-effective ways to save lives $[41,42]$. 
This study has several limitations that are mostly related to the comprehensiveness and validity of the secondary data we adopted. First, we were only able to include 64 low- and middle- income countries with available data. Therefore, the aggregate-level estimates were not representative at either global-level or by income groups. Second, due to the varying availability of data in the DHS by country, we were able to conduct a trend analysis only for a subset of countries, which limited our knowledge on how the share of deaths changed over time in developing countries. With more data available in the future, the aggregatelevel analysis could be strengthened. Third, although DHS has been widely adopted as the most reliable source on child mortality [9-11, 22], we recognize the potential data collection problems, including misreporting dates to birth or misreporting age at death [43].

\section{Conclusions}

Despite these limitations, this was the first study providing a comprehensive picture on the distribution of child deaths in each period of child development. Neonatal deaths accounted for around half of all under- 5 deaths, and appeared to be more concentrated in more affluent countries. Along with the countries' economic development, an increasing proportion of under- 5 deaths occurs in the neonatal period, suggesting a need for multi-layer health strategies with potentially heavier investment in newborn health, yet country-specific context should be considered in national policy discussions. Future research should explore a detailed assessment of costeffective interventions to alleviate death burden in each period, and guide the countries to develop multi-layered health strategies that are based on the country's specific context.

\section{Abbreviations}

GDP: Gross Domestic Product; PPs: Percentage points; MDG: Millennium Development Goal; SDG: Sustainable Development Goal; DHS: Demographic and Health Survey; LIC: Low-income country; LMIC: Lower-middle-income country; UMIC: Upper-middle income country

\section{Supplementary Information}

The online version contains supplementary material available at https://doi. org/10.1186/s12939-021-01449-8.

Additional file 1: Table 1. Share of neonatal, postneonatal, and childhood to total under-5 deaths. Table 2. Share of neonatal, postneonatal, and childhood to total under-5 deaths at aggregate-level, latest survey rounds between 2008 and 2018. Table 3. Share of neonatal, postneonatal, and childhood to total under-5 deaths at aggregate-level including the countries with 0 recorded deaths in any period of life, latest survey rounds. Table 4. Change in share of neonatal to total under-5 deaths. Table 5. Change in share of postneonatal to total under-5 deaths. Table $\mathbf{6}$. Change in share of childhood to total under-5 deaths.

\section{Acknowledgements}

The authors acknowledge the support of the DHS Program at ICF (www. dhsprogram.com) for providing access to the data.

\section{Authors' contributions}

SVS conceptualized and designed the study. ZL, RK and OK contributed to the conceptualization and the design. ZL led the data analysis, interpretation of the results and led the writing. OK, RK and SVS contributed to the interpretation of the results and writing. All the authors approved the final submission of the study. SVS provided overall supervision to the study.

\section{Funding}

None.

Availability of data and materials

DHS data are available at https://dhsprogram.com (requiring a simple application).

\section{Declarations}

Ethics approval and consent to participate

This analysis was reviewed by the Harvard T.H. Chan School of Public Health Institutional Review Board and was considered exempt from full review because the study was based on an anonymous public use dataset with no identifiable information on the survey participants.

\section{Consent for publication}

N/A.

\section{Competing interests}

The authors have no conflicts of interest relevant to this article to disclose.

\section{Author details}

${ }^{1}$ Vanke School of Public Health, Tsinghua University, Beijing 100084, China. ${ }^{2}$ Department of Social and Behavioral Sciences, Harvard T.H. Chan School of Public Health, 677 Huntington Avenue, Boston, MA 02115, USA. ${ }^{3}$ Takemi Program in International Health, Harvard T.H. Chan School of Public Health, 677 Huntington Avenue, Boston, MA 02115, USA. ${ }^{4}$ Department of Economic History, School of Economics and Management, Lund University, P.O. Box 7083, 22007 Lund, Sweden. ${ }^{5}$ Division of Health Policy \& Management, College of Health Science, Korea University, 145 Anam-ro, Seongbuk-gu, Seoul 02841, South Korea. ${ }^{6}$ Interdisciplinary Program in Precision Public Health, Department of Public Health Sciences, Graduate School of Korea University, Seoul 02841, South Korea. ${ }^{7}$ Harvard Center for Population and Development Studies, 9 Bow Street, Cambridge, MA 02138, USA.

Received: 22 January 2021 Accepted: 13 April 2021

Published online: 26 April 2021

References

1. WHO. Child mortality rates plunge by more than half since 1990 but global MDG target missed by wide margin: WHO; 2015. Available from: https:// www.who.int/mediacentre/news/releases/2015/child-mortality-report/en/. [cited 2020 Feb 4]

2. Brownell M, Enns J. Reducing child mortality in high-income countries: where to from here? Lancet (London, England). 2018;391:1968-9.

3. World Health Organization. Newborns: reducing mortality. Available from: https://www.who.int/news-room/fact-sheets/detail/newborns-reducingmortality. [cited 2020 Feb 4].

4. WHO | Neonatal mortality: trends 1990-2010. WHO. 2011; Available from: https://www.who.int/maternal_child_adolescent/topics/newborn/neonatal_ mortality/en/. [cited 2020 Feb 4].

5. Judkins A. Global neonatal mortality - can we do more? Pediatrics. 2018; 141:466.

6. Lassi ZS, Salam RA, Das JK, Bhutta ZA. Essential interventions for maternal, newborn and child health: background and methodology. Reprod Health. 2014:11(Suppl 1):S1. https://doi.org/10.1186/1742-4755-11-S1-S1.

7. Lassi ZS, Middleton PF, Crowther C, Bhutta ZA. Interventions to improve neonatal health and later survival: an overview of systematic reviews. EBioMedicine. 2015;2(8):985-1000. https://doi.org/10.1016/j.ebiom.2015.05.023. 
8. Lassi ZS, Mallick D, Das JK, Mal L, Salam RA, Bhutta ZA. Essential interventions for child health. Reprod Health. 2014;11:S4.

9. Rajaratnam JK, Marcus JR, Flaxman AD, Wang H, Levin-Rector A, Dwyer L, et al. Neonatal, postneonatal, childhood, and under-5 mortality for 187 countries, 1970-2010: a systematic analysis of progress towards millennium development goal 4. Lancet. 2010;375(9730):1988-2008. https://doi.org/10.1 016/50140-6736(10)60703-9.

10. Wang H, Bhutta ZA, Coates MM, Coggeshall M, Dandona L, Diallo K, et al. Global, regional, national, and selected subnational levels of stillbirths, neonatal, infant, and under-5 mortality, 1980-2015: a systematic analysis for the global burden of disease study 2015. Lancet. 2016;388(10053):1725-74. https://doi.org/10.1016/50140-6736(16)31575-6.

11. Wang H, Liddell CA, Coates MM, Mooney MD, Levitz CE, Schumacher AE, et al. Global, regional, and national levels of neonatal, infant, and under-5 mortality during 1990-2013: a systematic analysis for the global burden of disease study 2013. Lancet. 2014;384(9947):957-79. https://doi.org/10.1016/ S0140-6736(14)60497-9.

12. Mejía-Guevara I, Zuo W, Bendavid E, Li N, Tuljapurkar S. Age distribution, trends, and forecasts ofunder-5 mortality in 31 sub-saharan africancountries: a modeling study. PLoS Med. 2019;16(3):e1002757. https://doi.org/10.1371/ journal.pmed.1002757.

13. United Nations. Sustainable Development Goals. Available from: https:// www.un.org/sustainabledevelopment/health/. [cited 2018 Jul 14].

14. UN Inter-agency Group for Child Mortality Estimation. Levels \& trends in child mortality report 2019. 2019. Available from: https://www.unicef.org/ media/60561/file/UN-IGME-child-mortality-report-2019.pdf

15. UN Inter-agency Group for Child Mortality Estimation. Levels \& trends in child mortality report 2017. 2017.

16. UN Inter-agency Group for Child Mortality Estimation. Levels \& Trends in Child Mortality Report 2020. Available from: https://www.unicef.org/media/ 79371/file/UN-IGME-child-mortality-report-2020.pdf.pdf. Cited 2020 Feb 4.

17. Subramanian S, Corsi DJ, Subramanyam MA, Davey SG. Jumping the gun: the problematic discourse on socioeconomic status and cardiovascular health in India. Int J Epidemiol. 2013;42(5):1410-26. https://doi.org/10.1093/ ije/dyt017.

18. Gwatkin DR. Metrics matter: the case of assessing the importance of noncommunicable diseases for the poor. Int J Epidemiol. 2013;42(5):1211-4. https://doi.org/10.1093/ije/dyt167.

19. Gwatkin DR, Guillot M, Heuveline P. The burden of disease among the global poor. Lancet. 1999;354(9178):586-9. https://doi.org/10.1016/S01406736(99)02108-X.

20. Ozaltin E, Hill K, Subramanian SV. Association of maternal stature with offspring mortality, underweight, and stunting in low- to middle-income countries. JAMA. 2010;303(15):1507-16. https://doi.org/10.1001/jama.2010.450.

21. Chao F, You D, Pedersen J, Hug L, Alkema L. National and regional under-5 mortality rate by economic status for low-income and middle-income countries: a systematic assessment. Lancet Glob Heal. 2018;6(5):e535-47. https://doi.org/10.1016/S2214-109X(18)30059-7.

22. Li Z, Li M, Subramanian SV, Lu C. Assessing levels and trends of child health inequality in 88 developing countries: from 2000 to 2014. Glob Health Action. 2017;10(1):1408385. https://doi.org/10.1080/16549716.2017.1408385.

23. USAID. The DHS Program - Available Datasets. Available from: https://www. dhsprogram.com/data/available-datasets.cfm. [cited 2019 Jul 25].

24. Turner AG. Sampling strategies. 2003. Available from: http://mdgs.un.org/ unsd/demographic/meetings/egm/Sampling_1203/docs/no_2.pdf. [cited 2019 Nov 7]

25. The World Bank. GDP per capita (current US\$) | Data. Available from: https:// data.worldbank.org/indicator/NY.GDP.PCAP.CD. [cited 2018 Dec 11]

26. The World Bank. PPP conversion factor, GDP (LCU per international \$). Available from: https://data.worldbank.org/indicator/pa.nus.ppp. [cited 2020 May 1]

27. The World Bank. World Bank Country and Lending Groups - World Bank Data Help Desk. Available from: https://datahelpdesk.worldbank.org/ knowledgebase/articles/906519-world-bank-country-and-lending-groups. [cited 2020 Sep 2]

28. Guthold R, Stevens GA, Riley LM, Bull FC. Worldwide trends in insufficient physical activity from 2001 to 2016: a pooled analysis of 358 populationbased surveys with 1.9 million participants. Lancet Glob Heal. 2018;6(10): e1077-86. https://doi.org/10.1016/S2214-109X(18)30357-7.

29. Cousens S, Blencowe H, Stanton C, Chou D, Ahmed S, Steinhardt L, Creanga AA, Tunçalp Ö, Balsara ZP, Gupta S, Say L. National, regional, and worldwide estimates of stillbirth rates in 2009 with trends since 1995: a systematic analysis. Lancet. 2011;377(9774):1319-30.

30. Vollmer S, Harttgen K, Subramanyam MA, Finlay J, Klasen S, Subramanian SV Association between economic growth and early childhood undernutrition: evidence from 121 demographic and health surveys from 36 low-income and middle-income countries. Lancet Glob Heal. 2014;2(4):e225-34. https:// doi.org/10.1016/S2214-109X(14)70025-7.

31. The World Bank. Population, total | Data. Available from: https://data. worldbank.org/indicator/SP.POP.TOTL. [cited 2020 May 10].

32. Ahmed M, Won Y. Cross-National systematic review of neonatal mortality and postnatal newborn care: special focus on Pakistan. Int J Environ Res Public Health. 2017;14(12). https://doi.org/10.3390/ijerph14121442.

33. Kandel N, Lamichhane J. Female health volunteers of Nepal: the backbone of health care. Lancet. 2019;393(10171):e19-20. https://doi.org/10.1016/S014 0-6736(19)30207-7.

34. Paudel D, Shrestha IB, Siebeck M, Rehfuess E. Impact of the community-based newborn care package in Nepal: a quasi-experimental evaluation. BMJ Open. 2017;7(10):e015285. https:/doi.org/10.1136/bmjopen-2016-015285.

35. Saadat S, Cortez R, Voetberg A, Chowdhury S, Sarker I. Achieving MDGs 4 \& 5: Nepal's progress on maternal and child health. Heal Nutr Popul Knowl Briefs. 2014. http://documents1.worldbank.org/curated/en/330361468291 004228/text/922740BRIOBox30s0onOMCHOAugust02014.txt. (Cited 2021 April 19).

36. Hug L, Alexander M, You D, Alkema L. National, regional, and global levels and trends in neonatal mortality between 1990 and 2017, with scenariobased projections to 2030: a systematic analysis. Lancet Glob Heal. 2019;7(6): e710-20. https://doi.org/10.1016/S2214-109X(19)30163-9.

37. Profit J, Lee D, Zupancic JA, Papile L, Gutierrez C, Goldie SJ, et al. Clinical benefits, costs, and cost-effectiveness of neonatal intensive care in Mexico. PLoS Med. 2010;7(12):e1000379. https:/doi.org/10.1371/journal.pmed.1000379.

38. Maredza M, Chola L, Hofman K. Economic evaluations of interventions to reduce neonatal morbidity and mortality: a review of the evidence in LMICS and its implications for South Africa. Cost Eff Resour Alloc. 2016;14(1):2. https://doi.org/10.1186/s12962-015-0049-5.

39. Lassi ZS, Bhutta ZA. Community-based intervention packages for reducing maternal and neonatal morbidity and mortality and improving neonatal outcomes. Cochrane Database Syst Rev. 2015;3:CD007754.

40. Nkonki LL, Chola LL, Tugendhaft AA, Hofman KK. Modelling the cost of community interventions to reduce child mortality in South Africa using the lives saved tool (LiST). BMJ Open. 2017;7(8):e011425. https://doi.org/10.1136/ bmjopen-2016-011425.

41. Black RE, Levin C, Walker N, Chou D, Liu L, Temmerman M, Group DR. Reproductive, maternal, newborn, and child health: key messages from disease control priorities 3rd edition. Lancet. 2016;388(10061):2811-24.

42. Gilmore B, McAuliffe E. Effectiveness of community health workers delivering preventive interventions for maternal and child health in lowand middle-income countries: a systematic review. BMC Public Health. 2013; 13(1). https://doi.org/10.1186/1471-2458-13-847.

43. Mwale MW. Infant and child mortality. . Available from: https://dhsprogram. com/pubs/pdf/fr175/08chapter08.pdf. [cited 2018 Oct 6]

\section{Publisher's Note}

Springer Nature remains neutral with regard to jurisdictional claims in published maps and institutional affiliations.

\section{Ready to submit your research? Choose BMC and benefit from:}

- fast, convenient online submission

- thorough peer review by experienced researchers in your field

- rapid publication on acceptance

- support for research data, including large and complex data types

- gold Open Access which fosters wider collaboration and increased citations

- maximum visibility for your research: over $100 \mathrm{M}$ website views per year

At BMC, research is always in progress.

Learn more biomedcentral.com/submissions 